\begin{tabular}{|cl}
\hline Jurnal Teknologi Kimia Unimal & $\begin{array}{l}\text { Jurnal } \\
\text { Teknologi } \\
\text { Kimia } \\
\text { Unimal }\end{array}$ \\
\hline
\end{tabular}

\title{
Aplikasi Kontrol PID pada Reaktor Pabrik Asam Formiat dengan Kapasitas 100.000 Ton/Tahun
}

\author{
Nasrul Z.A, Yonita Putri Roja, Novi Sylvia \\ Jurusan Teknik Kimia, Fakultas Teknik, Universitas Malikussaleh \\ Kampus Utama Cot Teungku Nie Reuleut, Muara Batu, Aceh Utara - 24355 \\ Korespondensi: HP: 085260046742, e-mail: nxsylvia@gmail.com
}

\begin{abstract}
Abstrak
Continuous Stirred Tank Reactor (CSTR) atau Reaktor Alir Tangki Berpengaduk (RATB) merupakan salah satu jenis reaktor yang umumnya berbentuk bejana dan bekerja secara kontinyu. Continuous Stirred Tank Reactor (CSTR) banyak digunakan untuk reaksi-reaksi homogen fase cair tanpa katalis maupun dengan katalis. Penelitian ini bertujuan untuk mendapatkan respon terbaik kontrol PID dengan menggunakan metode trial and error pada nilai $\mathrm{Kc}$, Ti, dan Td. Metode trial and error adalah adalah metode mencari nilai parameter dengan cara mencoba-coba suatu nilai tertentu sebagai parameter sampai didapat sebuah performansi kontrol PID yang terbaik. Sistem kontrol PID merupakan controller untuk menentukan presisi suatu sistem instrumentasi dengan karakteristik adanya umpan balik pada sistem tersebut (Feed back). Adapun metodologi penelitian ini adalah membuat model steady state Continuous Stirred Tank Reactor (CSTR), kemudian mengubah model steady state menjadi model dynamic, lalu membuat model kontrol PID, setelah itu melakukan tuning terhadap kontrol PID dan melakukan pengujian terhadap kontrol PID, dengan melakukan gangguan pada set point. Nilai $K c=8, T i=1$ dan $T d=0$ respon waktu rata-ratanya 0,815 menit, sebuah sistem pengendalian suhu yang dapat diterapkan untuk mendapatkan waktu yang paling optimal. Nilai $K c=10, T i=4$ dan $T d=0$ waktu rata-ratanya 1,257 menit sebuah sistem pengendalian suhu yang memiliki waktu yang kurang optimal.
\end{abstract}

Kata Kunci: $\quad$ Continuous Stirred Tank Reactor (CSTR), PID, Set Point.

\begin{abstract}
Abstarct
To increasing the heating value of biogas and natural gas on industry needed a way to separate the carbon dioxide (CO2) use technology absorption. Many methods have been used to absorb the $\mathrm{CO} 2$ that has been researched, but most still use the absorption process in batch system. Therefore, this research will be conducted on the process of absorption of carbon dioxide $(\mathrm{CO} 2)$ and water $(\mathrm{H} 2 \mathrm{O})$ will be simulated using Computational Fluid Dynamic (CFD). This research aims to test the performance of column absorption absorption on the process of carbon dioxide (CO2) and uses Autodesk Inventor 2016 and Fluent 16.0 to model the
\end{abstract}


absorption and the pressure drop on the absorption column. This research was conducted with varying influence of the flow rate of water and carbon dioxide by comparison $2: 1$, i.e. CO2 117.75; $141.3 ; 188.4$ liters/min and $\mathrm{H} 2 \mathrm{O} 235.5 ; 282.6$ and 376.8 liters/minute.The results obtained show that the Percent of the maximum absorption i.e. $45.89 \%$ of flow rate of $\mathrm{CO} 2$ occurs at 117.75 liters/minute and $\mathrm{H} 2 \mathrm{O}$ at 235.5 litres/minute, while the percent the minimum absorption i.e. $28.32 \%$ occurred at a flow rate of CO2 188.4 liters/minute and $\mathrm{H} 2 \mathrm{O} 376.8$ liters/minute. T`he highest pressure drop occurs at 188.4 flow rate liters/minute and $\mathrm{H} 2 \mathrm{O} 376.8$ liters/minute, with a value of $\Delta \mathrm{P} 0.66 \mathrm{~atm}$, while the lowest pressure drop occurs at $177.75 \mathrm{CO} 2$ flow rate in litres/minute and $\mathrm{H} 2 \mathrm{O}$ at 235.5 litres/minute with the value of $\Delta \mathrm{P} 0.17 \mathrm{~atm}$.

Key words: $\quad$ absorption, water, Computational Fluid Dynamic, carbon dioxide, pressure drop

\section{Pendahuluan}

Dalam perkembangannya penelitian CSTR telah banyak dilakukan. Dimulai dengan pengendalian CSTR menggunakan pengendali konvensional PID untuk mengendalikan temperatur. Kontrol Proporsional Integral Derivatif (PID) adalah kontroler yang menggabungkan kontroler proporsional, integral dan derivatif. Kontroler ini memiliki parameter-parameter pengontrol, yaitu Kp, Ti, dan Td. Ketiga parameter tersebut diturunkan dari perhitungan matematis pada metode PID konvensional. Kesulitan timbul bila plant yang dikendalikan adalah system dengan orde tinggi. Maka dari itu, diperlukan metode tuning PID yang dapat diterapkan dalam sistem orde tinggi (Wijaya et al.).

Sanposh (2008) mendesain feedback linearization controller dalam mengendalikan level pada CSTR. Pada penelitian ini kestabilan sistem tidak dapat dijamin karena kehadiran error steady state. Selain itu, feedback linearization controller mahal dalam implementasi. Teknik gain scheduling telah diterapkan pada CSTR untuk mengendalikan level. Pada penelitian ini terdapat waktu transient yang lambat dikarenakan gain penjadwalan pengendali yang dipilih untuk titik operasi adalah konstan, tetapi faktanya lintasan transient dari sistem CSTR beroperasi lebih jauh atau bahkan lebih dekat dari titik operasi sebenarnya. 
Banu (2007) mengkombinasikan gain scheduling dengan pengendali fuzzy logic untuk mengendalikan temperatur pada sistem CSTR. Pengendali cerdas fuzzy logic digunakan untuk mengatasi masalah waktu transient sistem CSTR dan gain schedule yang tepat untuk tiap-tiap kondisi operasi yang berbeda. Kelemahan pada penelitian ini adalah pengendali fuzzy logic terbatas dalam analisis.

Leonid dan Jeffrey (2003) melakukan penelitian untuk mengendalikan konsentrasi pada sistem CSTR menggunakan Sliding Mode Controller. Kelemahan pada penelitian ini adalah kehadiran chattering sebagai akibat dari penggunaan pengendali sliding mode. Kehadiran chattering menyebabkan kestabilan sistem terganggu dan error steady state yang cukup besar.

Herlambang (2010) mendisain pengendali Sliding Mode (SM) untuk mengendalikan level dan temperatur dalam Steam Drum Boiler. Pada penelitian ini Herlambang membagi SMC menjadi static SMC dan dynamic SMC (Utara, 2005).

Sampai saat ini kontrol PID (Proporsional Integral Derivative) merupakan satu-satunya strategi yang paling banyak digunakan pada pengontrolan proses industri. Berdasarkan survey, 97\% industri yang bergerak dalam bidang proses (seperti industri kimia, pulp, makanan, minyak dan gas) menggunakan PID sebagai komponen utama dalam pengontrolannya.

Kepopuleran PID sebagai komponen kontrol proses dilatar belakangi terutama oleh kesederhanaan struktur serta kemudahan dalam melakukan tuning parameter kontrolnya. Selain sederhana, kepopuleran PID disebabkan juga oleh alasan histories. Dalam hal ini, PID telah diterapkan di industri secara luas jauh sebelum era digital berkembang yaitu dimulai sekitar tahun 1930-an, dimana saat itu strategi kontrol PID diimplementasikan dengan menggunakan rangkaian elektronika analog, bahkan banyak diantaranya direalisasikan dengan menggunakan komponen mekanis dan pneumatis murni. Seiring dengan perkembangan teknologi digital dan solid state, dewasa ini produk PID komersil 
muncul di pasaran dalam beragam model dan bentuk, yaitu dari sekedar model jenis special purpose process controller (seperti Temperature Controler, Pressure Controller, dan sebagainya) sampai modul kontrol jenis general purpose process controller atau yang lebih dikenal dengan nama DCS (Distributed Control System). Bahkan perkembangan terakhir, modul PID ini juga umum dijumpai dalam bentuk modul independen pada sistem PLC (Programmable Logic Controller) (Setiawan, 2008).

Reaktor sebagai tempat berlangsungnya suatu reaksi kimia, sering dinyatakan sebagai pusat suatu proses kimia. Berbagai jenis reaktor dapat dibedakan atas dasar bentuk reaktor yang digunakan, proses yang berlangsung, atau kondisi operasinya. Reaktor alir tangki berpengaduk (RATB) atau dikenal sebagai continuous stirred tank reactor (CSTR) merupakan salah satu jenis reaktor yang umumnya berbentuk bejana dan bekerja secara kontinu (alir), dan banyak digunakan untuk reaksi-reaksi homogen fase cair tanpa katalis maupun dengan katalis, serta reaksi yang terjadi di dalamnya berlangsung secara isotermal (Purwanti, 2009).

Fokus penelitian ini ingin menentukan nilai parameter kontrol PID yang bekerja optimal menggunakan metode tuning manual trial error dengan menggunakan Aspen Hysis V8,6. Penelitian dilakukan ingin melihat apakah kontrol PID bisa bekerja maksimal dalam menstabilkan error jika diberi ganguan pada temperatur yang sudah ditetapkan pada reaktor.

Adapun tujuan penelitian ini yaitu untuk mendapatkan respon terbaik kontrol PID dengan metode trial and error pada nilai kc,ti, dan td pada alat reaktor CSTR pabrik asam formiat dengan kapasitas 100.000 ton/tahun.

\section{Tinjauan Pustaka}

\section{Continuous Stirred Tank Reactor (CSTR)}

Continuous Stirred Tank Reactor (CSTR) atau Reaktor Alir Tangki Berpengaduk (RATB) merupakan salah satu jenis reaktor yang umumnya 
berbentuk bejana dan bekerja secara kontinyu (alir). Continuous Stirred Tank Reactor (CSTR) banyak digunakan untuk reaksi-reaksi homogen fase cair tanpa katalis maupun dengan katalis, serta reaksi yang didalamnya berlangsung secara isothermal (Purwanti, 2009).

CSTR berbeda dengan reaktor lainnya, seperti PFR (plug flow reactors) dan PBR (packed bed reactors), karena adanya proses pengadukan (stirred) yang memungkinkan adanya distibusi sifat fisis dan kimiawi secara merata dari zat yang bereaksi di setiap tempat dalam reaktor. Penggunaan CSTR paling banyak digunakan untuk memproduksi polimer, seperti polimerisasi tyrene. Selain itu CSTR juga digunakan dalam pembentukan barium sulfat (BaSO4), asam asetat, asam formiat dan penanganan limbah (Agustinah, 2014).

\section{Proses Pengendalian Suhu CSTR}

Continuous Stirred Tank Reactor (CSTR) digunakan sebagai tangki pengaduk dan pencampuran sebuah produk dengan proses pemanasan. Suhu pemanasan pada CSTR dijaga pada suhu kerja tertentu sehingga diperoleh campuran produk yang tercampur secara sempurna. Dalam proses pembuatan Asam Formiat, suhu keluaran tangki CSTR dijaga konstan pada $80^{\circ} \mathrm{C}$ karena pada suhu $80{ }^{\circ} \mathrm{C}$ didapatkan kualitas pencampuran produk yang maksimal. Suhu kerja proses yang diperbolehkan pada pembuatan Asam Formiat ini tidak melebihi range suhu kerja proses, yaitu $80-85^{\circ} \mathrm{C}$.

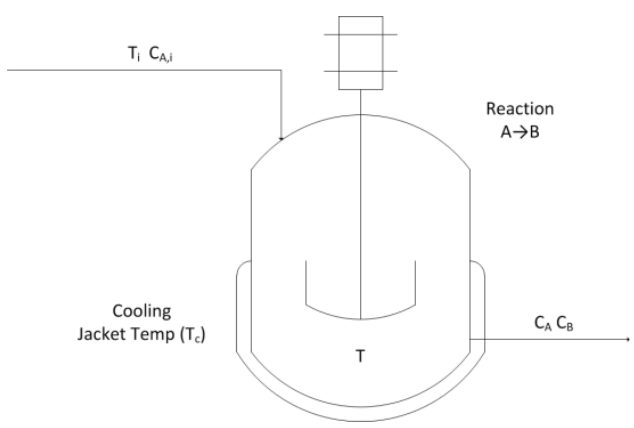

\section{Gambar 1 Continuous Stirred Tank Reactor (CSTR)}

Pengendalian suhu pada CSTR sangat penting dilakukan karena bila suhu terlalu tinggi atau suhu diatas kondisi steady state akan sangat berbahaya untuk 
dioperasikan atau juga dapat menguraikan produk menjadi komponen-komponen penyusunnya. Jika suhu terlalu rendah akan mengakibatkan produk tidak dapat tercampur dengan sempurna. Untuk mempertahankan suhu dalam tangki CSTR dapat dilakukan dengan mengalirkan steam yang dilewatkan pada sebuah koil/pipa yang terpasang didalam tangki tersebut atau dengan mensirkulasi condensate melalui alat penukar panas. Suatu kontroler dirancang untuk menjaga suhu keluaran tangki CSTR dengan mengendalikan aliran/flow steam kedalam tangki yaitu dengan mengatur bukaan valve sehingga mencapai nilai suhu kerja yang diinginkan (Agustinah, 2014).

\section{Sistem Kontrol}

Sistem kontrol adalah suatu sistem yang berfungsi untuk mengatur pengontrolan suatu plant dengan cara mengatur input-nya. Semua sistem kontrol memliliki kontroler dan actuator. Input pada kontroler biasanya disebut sebagai set point. Actuator pada alat elektromekanik mengambil sinyal dari kontroler dan diubah dalam bentuk mekanik. Diagram blok sistem control secara umum terdapat pada gambar di bawah ini.

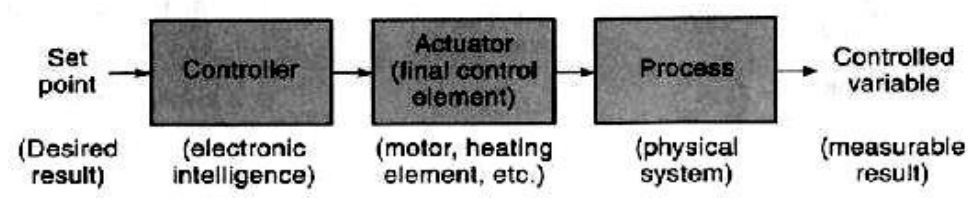

Gambar 2 Sistem Kontrol Industri

Tujuan dari sistem kontrol adalah mempertahankan nilai variabel proses agar sama dengan nilai yang diinginkan (set point). Tetapi tujuan tersebut sering tidak dapat atau sukar dipenuhi karena keterbatasan operasi dan kemampuan sistem pengendalian. Oleh sebab itu, tujuan praktis atau tujuan nyata sistem kontrol adalah mempertahankan nilai variabel proses di sekitar nilai yang diinginkan dalam batas-batas yang ditetapkan. Namun perlu diingat bahwa 
hakikat utama pengendalian proses dalam industri adalah untuk memperoleh hasil akhir proses produksi agar sesuai target. Tujuan pengendalian erat berkaitan dengan kualitas pengendalian yang didasarkan atas tanggapan variabel proses bila ada perubahan setpoint atau beban. Jika terjadi perubahan setpoint atau beban, variabel proses diharapkan:

a. secepat mungkin mencapai kondisi mantap (settling time sekecil mungkin);

b. setepat mungkin mencapai setpoint (offset sekecil mungkin); dan

c. sekecil mungkin terjadi osilasi (maximum error sekecil mungkin).

Sistem kontrol dapat digolongkan menjadi dua bagian, yaitu sistem kontrol loop terbuka (open loop) dan sistem kontrol tertutup (closed loop). Perbedaan sistem kontrol loop terbuka dan sistem kontrol loop tertutup adalah pada ada tidaknya feedback pada sistem. Jika suatu sistem memiliki feedback, maka outputnya akan berpengaruh pada proses kontrol. Kebanyakan sistem kontrol menggunakan istilah error sebagai feedback bagi sistem. Error adalah perbedaan dari nilai SP (Set Point) dan PV (Present Value). Kontroler yang sering digunakan, yaitu Kontroller PID yang merupakan gabungan dari tiga jenis kontroler, yaitu kontroler tipe P (Proportional), tipe I (Integral) dan tipe D (Defferential). Jika masing-masing dari ketiga kontroler tersebut berdiri sendirisendiri akan memberikan aksi control yang kurang bagus. Karena selain sifat ketiga kontroler tersebut saling bebas ketiganya juga saling mempunyai kelemahan dan kelebihan. Dengan mengkombinasikan ketiga jenis kontroler tersebut ke dalam satu kontroler diharapkan akan mampu memberikan performansi sistem sesuai yang diinginkan. Kontroler proporsional (Kp) memberikan efek mengurangi waktu naik, tetapi tidak menghapus kesalahan pada keadaan steady state, kontroler integral (Ti) akan memberi efek menghapus keadaan steady state, tetapi berakibat memburuknya respon peralihan, kontroler diferensial (Td) akan memberikan efek meningkatkan stabilitas sistem, mengurangi overshoot, dan menaikkan respons peralihan. 
Nasrul ZA dkk / Jurnal Teknologi Kimia Unimal 7 :2 (November 2018) 135 - 152

\section{PID Controller}

PID (Proporsional, Integral, Derivative) adalah pengontrolan dengan unsur P,I dan D berupa model matematika dengan masukan Gain+Integral+Derivative. PID merupakan pengontrolan konvensional, yang merupakan bentuk matematis yang sangat baik karena dapat mengubah error menjadi nol. Yaitu dengan menyamakan proses variabel sama dengan set point sehingga kestabilan pengontrolan dapat tercapai. Meskipun PID merupakan sistem pengontrolan yang paling unggul, namun ketiga parameter $\mathrm{P}, \mathrm{I}$ dan $\mathrm{D}$ satu sama lain memiliki kekurangan dan kelebihan, dapat saling mempengaruhi dan dapat juga berdiri sendiri ataupun gabungan ketiganya sehingga mendapatkan sinyal keluaran untuk sistem yang diinginkan, mengingat komponen dari sebuah kontroler merupakan gabungan dari detector kesalahan serta penguat sebagai penggerak.

\section{Metodologi Penelitian}

\section{Metode Trial and Error}

Salah satu cara yang sering digunakan untuk meningkatkan kestabilan suatu sistem industri adalah pengaplikasian kontrol PID. Kelebihan dari penggunaan kontrol PID adalah mudah diterapkan pada mikrokontroler atau PLC karena rumusnya yang sederhana. Namun PID juga memiliki kelemahan yaitu kita harus mencari nilai parameter $\mathrm{Kp}, \mathrm{Kd}$ dan $\mathrm{Ki}$ yang sesuai agar sistem control dapat bekerja dengan baik. Selama ini cara yang sering digunakan untuk mencari nilai $\mathrm{Kp}, \mathrm{Ki}$ dan $\mathrm{Kd}$ adalah dengan metode Trial and Error. Metode Trial and Error adalah metode mencari nilai parameter dengan cara mencoba-coba suatu nilai tertentu sebagai parameter sampai didapat sebuah performansi kontrol PID yang terbaik (Setiawan, 1997). Hal ini disebabkan karena parameter kp, ki, dan kd 
tidak independent. Untuk mendapatkan aksi control yang baik diperlukan langkah coba-coba dengan kombinasi antara P,I, dan D sampai ditemukan nilai kp, ki dan kd seperti yang diinginkan (Mulyawan, 2009). Tentu saja metode ini sangat memerlukan banyak waktu dan tenaga karena perlu mencoba memasukan banyak nilai sampai didapatkan hasil yang terbaik (Setiawan, 1997).

Pada metode trial and error diperlukan rekomendasi nilai parameter $\mathrm{Kc}$,Ti, dan Td agar membantu peneliti dalam menentukan kc, ti, dan td terbaik. Pada Tabel 1 merupakan rekomendasi nilai parameter kc,ti, dan td dari Jump Start: Aspen HYSYS ® Dynamics V7. 3

Tabel 1 PID Tuning Recommendations

\begin{tabular}{|l|c|c|c|}
\hline Sistem & Kc & Ti & Td \\
\hline Flow & 0,1 & 0,2 & 0 \\
\hline Level & 2 & 10 & 0 \\
\hline Pressure & 2 & 2 & 0 \\
\hline Temperature & 1 & 20 & 0 \\
\hline
\end{tabular}

(Jump Start: Aspen HYSYS ® Dynamics V7. 3)

\section{Aplikasi yang digunakan}

Aplikasi yang digunakan dalam penelitian ini adalah adalah Software Aspen Hysys V8.6

\section{Variabel Penelitian}

Variabel yang digunakan dalam penelitian ini terdiri dari variabel bebas, variabel tetap dan variabel terikat. Variabel bebas dalam penelitian ini adalah parameter Kc yaitu 8, 9, dan 10, parameter Ti yaitu 1, 2, 3, dan 4. Variabel tetap adalah temperatur keluaran reactor CSTR, waktu mencapai set point, konversi pada reactor CSTR, Error pada kontrol PID. Variabel terikat yang digunakan dalam penelitian ini adalah set point temperature control yaitu $80{ }^{\circ} \mathrm{C}$, Gangguan pada set point yaitu $79{ }^{\circ} \mathrm{C}$ dan $81{ }^{\circ} \mathrm{C}$. 


\section{Alur Penelitian}

Adapun langkah-langkah penelitiannya adalah sebagai berikut membuat model steady state reactor CSTR, mengubah model steady state menjadi model dynamic reactor CSTR, membuat model kontrol PID, melakukan tuning terhadap kontrol PID, melakukan pengujian terhadap kontrol PID

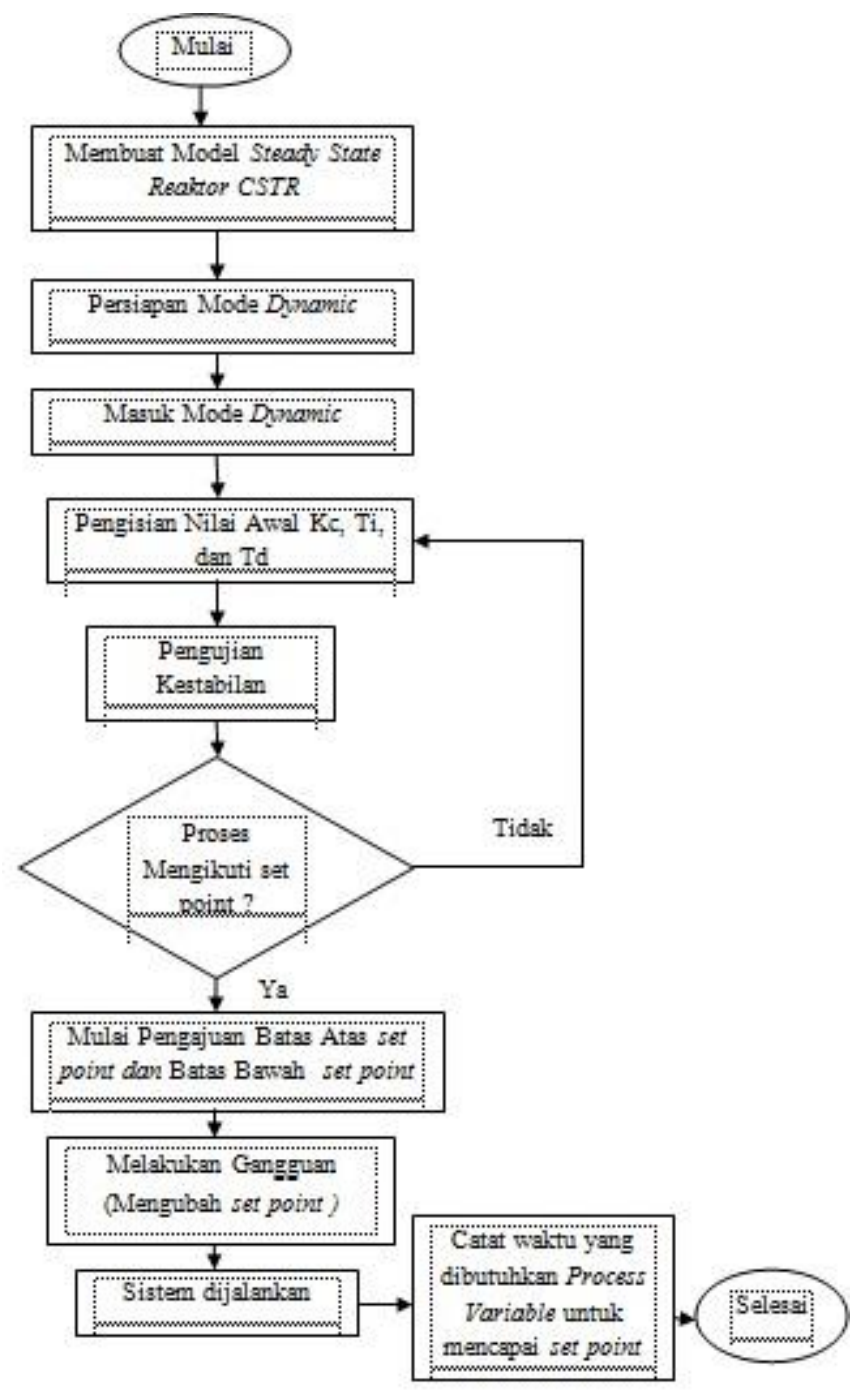

Gambar 3 Bagan Langkah Penelitian

Tabel 2, Pengujian Kontrol PID Nilai $\mathrm{Kc}=8, \mathrm{Ti}=1, \mathrm{Td}=0$, dimana dengan suhu $80{ }^{\circ} \mathrm{C}$ menuju suhu $79{ }^{\circ} \mathrm{C}$ didapat nilai error sebesar $-0,425$, konversi sebesar 96,62\%, dan respon waktu 0,604 menit, pada suhu $79^{\circ} \mathrm{C}$ menuju suhu 80 ${ }^{\circ} \mathrm{C}$ didapat nilai error sebesar 0,09 dengan konversi sebesar 96,60\%, dan respon 
waktu 0,906 menit, pada suhu $80{ }^{\circ} \mathrm{C}$ menuju suhu $81^{\circ} \mathrm{C}$ didapat nilai error sebesar 0,434 dengan konversi sebesar 96,58 \%, dan respon waktu 0,968 menit, pada suhu $81{ }^{\circ} \mathrm{C}$ menuju suhu $80{ }^{\circ} \mathrm{C}$ didapat nilai error sebesar $-0,413$ dengan konversi sebesar 96,60 \%, dan respon waktu 0,782 menit. Pada pengujian kontrol PID dengan nilai $\mathrm{Kc}=8, \mathrm{Ti}=1, \mathrm{Td}=0$ didapatkan respon waktu rata-rata 0,815 menit.

\section{Hasil dan Pembahasan}

Tabel 2 Hasil Pengujian Kontrol PID Nilai $\mathrm{Kc}=8, \mathrm{Ti}=1, \mathrm{Td}=0$

\begin{tabular}{|c|c|c|c|c|c|c|}
\hline $\begin{array}{l}\text { Suhu } \\
\left({ }^{\circ} \mathrm{C}\right)\end{array}$ & $\mathrm{Kc}$ & $\begin{array}{l}\mathrm{T} \\
\mathrm{i}\end{array}$ & $\mathrm{Td}$ & Error & Konversi (\%) & $\begin{array}{l}\text { Waktu } \\
\text { (menit) }\end{array}$ \\
\hline $80-79$ & \multirow{4}{*}{8} & \multirow{4}{*}{1} & \multirow{4}{*}{0} & $-0,425$ & 96,62 & 0,604 \\
\hline $79-80$ & & & & 0,09 & 96,60 & 0,906 \\
\hline $80-81$ & & & & 0,434 & 96,58 & 0,968 \\
\hline $81-80$ & & & & $-0,413$ & 96,60 & 0,782 \\
\hline \multicolumn{6}{|c|}{ Rata-Rata } & 0,815 \\
\hline
\end{tabular}

Tabel 3 Hasil Pengujian Kontrol PID Nilai $\mathrm{Kc}=10, \mathrm{Ti}=4, \mathrm{Td}=0$

\begin{tabular}{|c|c|c|c|c|c|c|}
\hline $\begin{array}{c}\text { Suhu } \\
\left({ }^{\circ} \mathrm{C}\right)\end{array}$ & Kc & Ti & Td & Error & Konversi (\%) & Waktu (menit) \\
\hline $80-79$ & & & & $-0,398$ & 96,62 & 1 \\
\hline $79-80$ & & & & 0,054 & 96,60 & 1,562 \\
\hline $80-81$ & \multirow{2}{*}{10} & \multirow{3}{*}{4} & \multirow{3}{*}{0} & 0,127 & 96,58 & 1,156 \\
\hline $81-80$ & & & & $-0,185$ & 96,60 & 1,313 \\
\hline \multicolumn{7}{|c|}{ Rata-Rata } \\
\hline
\end{tabular}

Tabel 3 Pengujian Kontrol PID Nilai $\mathrm{Kc}=10, \mathrm{Ti}=4, \mathrm{Td}=0$, dimana pada suhu $80{ }^{\circ} \mathrm{C}$ menuju suhu $79{ }^{\circ} \mathrm{C}$ didapat nilai error sebesar $-0,398$ dengan konversi 
sebesar 96,62\%, dan respon waktu 1 menit, pada suhu $79^{\circ} \mathrm{C}$ menuju suhu $80{ }^{\circ} \mathrm{C}$ didapat nilai error sebesar 0,054 dengan konversi sebesar 96,60 \%, dan respon waktu 1,562 menit, pada suhu $80^{\circ} \mathrm{C}$ menuju suhu $81{ }^{\circ} \mathrm{C}$ didapat nilai error sebesar 0,127 dengan konversi sebesar 96,58 \%, dan respon waktu 1,156 menit, pada suhu $81{ }^{\circ} \mathrm{C}$ menuju suhu $80{ }^{\circ} \mathrm{C}$ didapat nilai error sebesar $-0,185$ dengan konversi sebesar 96,60 \%, dan respon waktu 1,313 menit. Pada pengujian kontrol PID nilai $\mathrm{Kc}=10, \mathrm{Ti}=4, \mathrm{Td}=0$ didapatkan respon waktu rata-rata 1,257 menit.

Penelitian ini bertujuan untuk mendapatkan respon terbaik kontrol PID dengan menggunakan metode trial and error pada nilai kc, ti, dan td. Metode trial and error adalah adalah metode mencari nilai parameter dengan cara mencobacoba suatu nilai tertentu sebagai parameter sampai didapat sebuah performansi kontrol PID yang terbaik (Setiawan, 1997).

Penelitian model kontrol PID ini dilakukan pada alat reactor CSTR pabrik asam formiat kapasitas 100.000 ton/tahun. Dengan kondisi proses yang bersifat dinamik yang berarti tiap waktu dapat berubah-ubah dan perubahan sedikit pada kondisi proses dapat berakibat fatal bagi sebuah pabrik, maka dalam pengujian ini akan dilihat respon waktu, nilai error, dan persen konversi dari model control dengan memvariasikan nilai setpoint pada range temperatur $\left(79^{\circ} \mathrm{C}\right.$ dan $\left.81^{\circ} \mathrm{C}\right)$.

Pada penelitian controller PID, dalam menentukan nilai $\mathrm{Kc}, \mathrm{Ti}$, dan $\mathrm{Td}$ yang sesuai digunakan metode trial and error. Dimana metode trial and error adalah metode mencari nilai parameter dengan cara mencoba-coba suatu nilai tertentu sebagai parameter sampai didapat performansi control PID yang terbaik (Setiawan, 2009). Pada metode trial and error diperlukan rekomendasi nilai parameter Kc,Ti, dan Td agar membantu peneliti dalam menentukan Kc, Ti, dan Td terbaik. Rekomendasi nilai parameter kc,ti, dan td dari Jump Start: Aspen HYSYS $®$ Dynamics V7. 3 untuk suhu adalah $\mathrm{Kc}=1$, Ti $=20$, dan $\mathrm{Td}=0$. Gambar 4.3 merupakan gambar grafik dengan menggunakan nilai kc, Ti, dan Td dengan menggunakan nilai $\mathrm{Kc}$, Ti, dan Td dari Jump Start: Aspen HYSYS ${ }^{\circledR}$ Dynamics V7. 3 


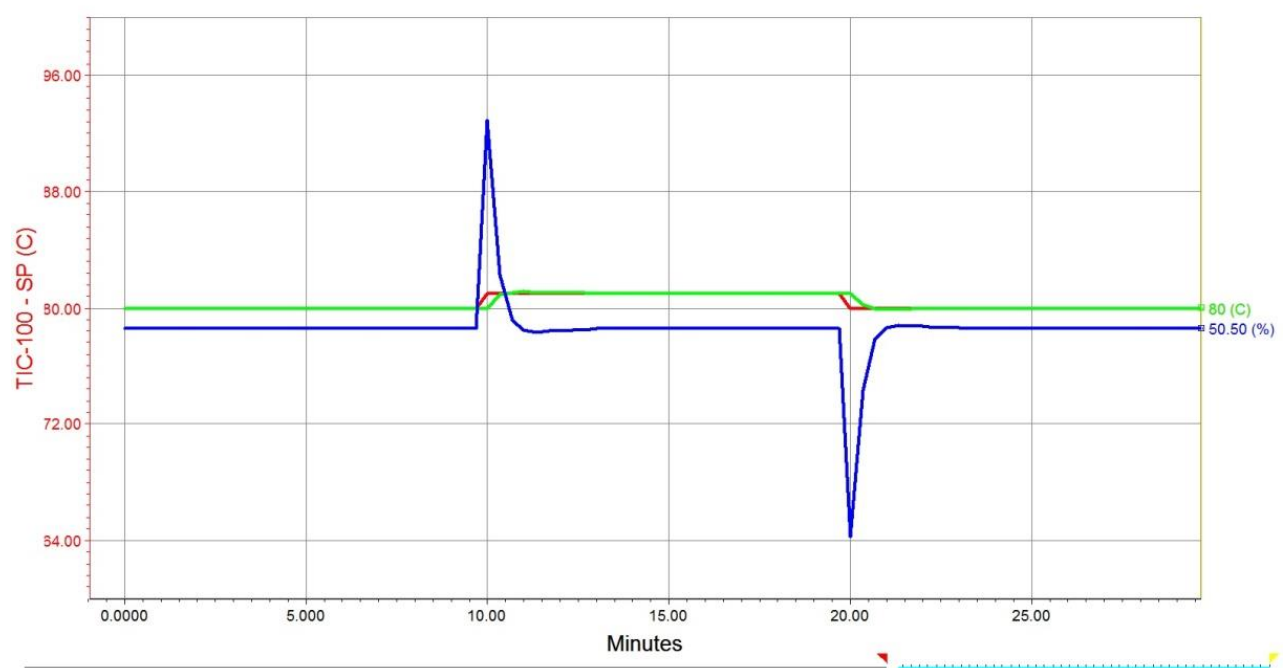

Gambar 4 grafik nilai $\mathrm{Kc}=1, \mathrm{Ti}=20$, dan $\mathrm{Td}=0$

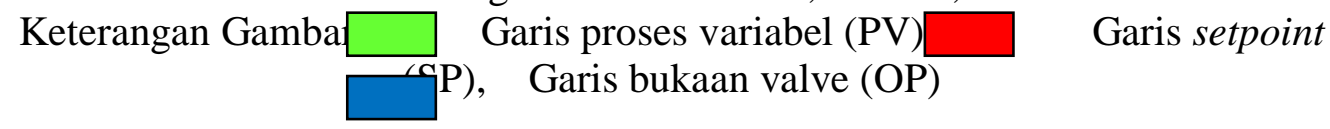

Berdasarkan gambar 4 dapat dilihat bahwa pada saat suhu diganggu menjadi $81^{\circ} \mathrm{C}$ waktu yang dibutuhkan PV untuk mencapai setpoint sangat lama yaitu 2,75 menit. Hal ini akan mengakibatkan kerugian terhadap pabrik yang mana akan mempengaruhi kualitas dari produk itu sendiri. Selanjutnya yaitu mencoba-coba nilai $\mathrm{Kc}$, Ti, dan Td dengan menggunakan gangguan yang sama dengan nilai Kc, Ti, dan Td dari Jump Start: Aspen HYSYS ® Dynamics V7. 3 sehingga didapatkan nilai $\mathrm{Kc}, \mathrm{Ti}$, dan $\mathrm{Td}$ terbaik untuk mendapatkan respon waktu yang cepat. Pada gambar 4.4 merupakan nilai Kc, Ti, dan Td dengan waktu respon yang cepat menggunakan gangguan yang sama dengan nilai $\mathrm{Kc}=8, \mathrm{Ti}=$ 1, dan $\mathrm{Td}=0$.

Berdasarkan Gambar 5 dapat dilihat bahwa pada saat suhu diganggu menjadi $81^{\circ} \mathrm{C}$ waktu yang dibutuhkan PV untuk mencapai setpoint sangat cepat yaitu 0,968 menit. Pada nilai $\mathrm{Kc}=8, \mathrm{Ti}=1$, dan $\mathrm{Td}=0$ merupakan respon waktu yang tercepat sehingga nilai $\mathrm{Kc}=8, \mathrm{Ti}=1$, dan $\mathrm{Td}=0$ diuji dengan memberikan gangguan suhu yaitu $79^{\circ} \mathrm{C}$ dan $80^{\circ} \mathrm{C}$. 


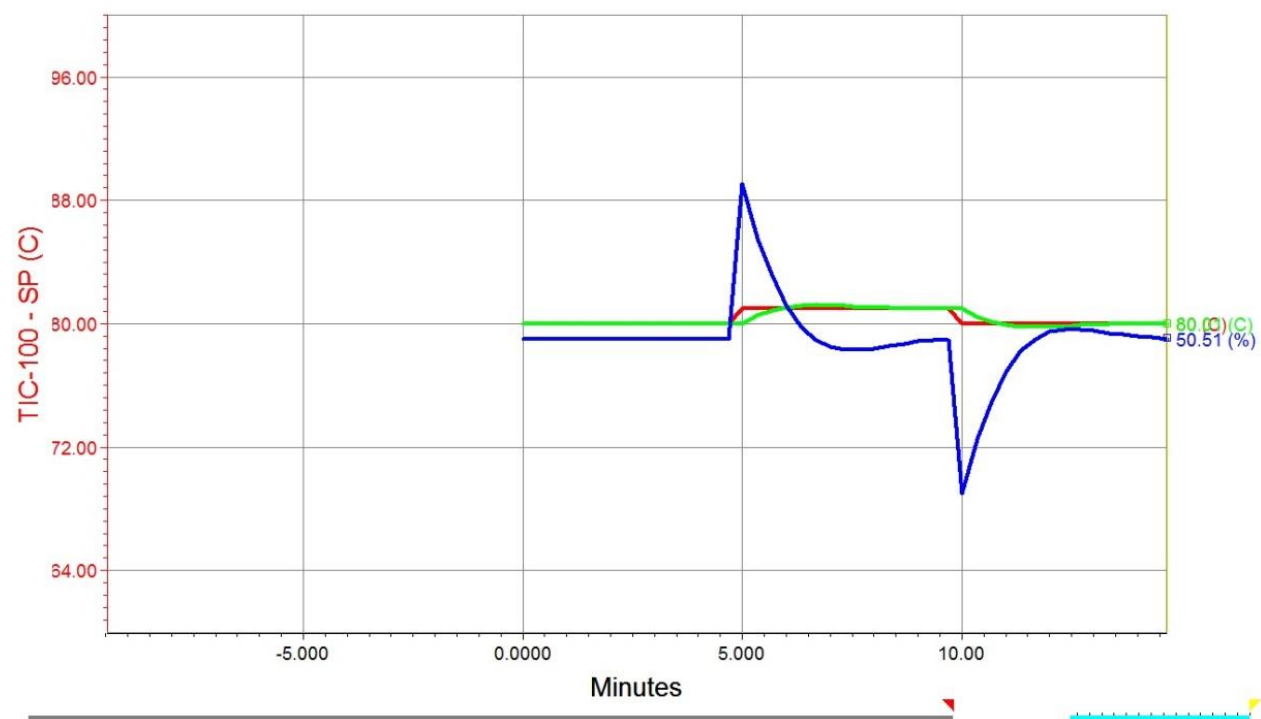

Gambar 5 grafik nilai $\mathrm{Kc}=8, \mathrm{Ti}=1$, dan $\mathrm{Td}=0$

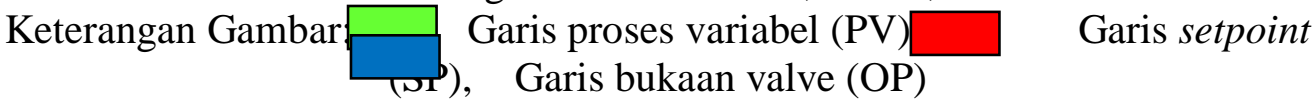

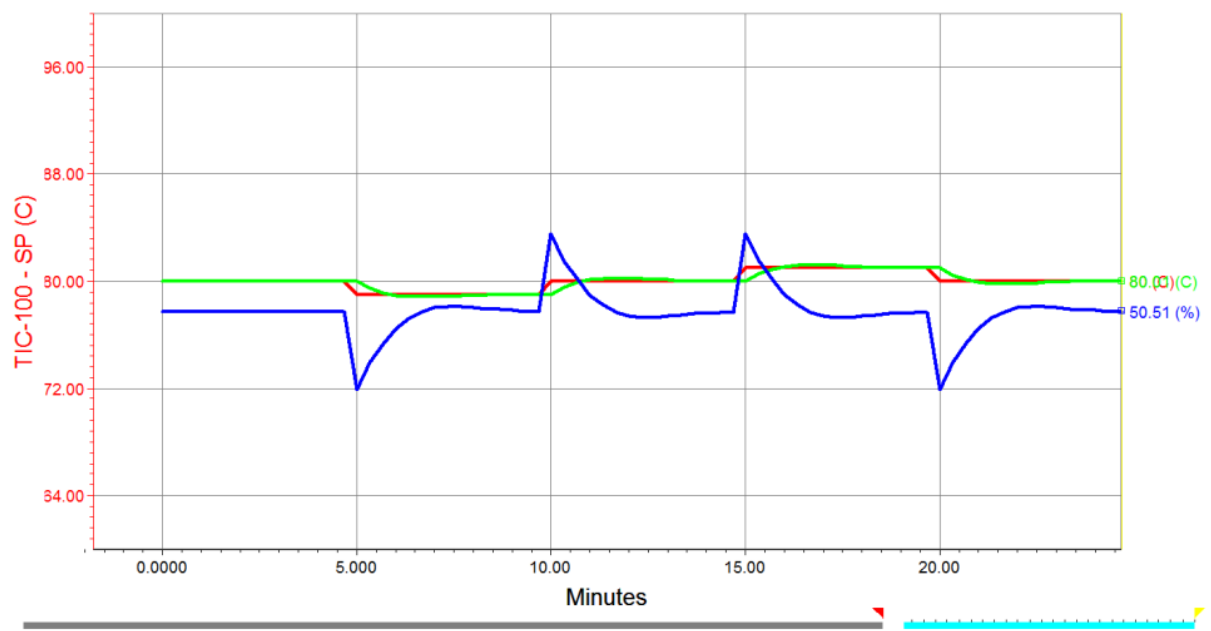

Gambar 5 Grafik hasil pengujian model PID dengan nilai $\mathrm{Kc}=8, \mathrm{Ti}=1$, (PV) $\quad$ Keterangan Gambar: $\quad$ Garis proses

Data yang terdapat pada Tabel 3 diuji dalam bentuk grafik model PID seperti terlihat pada Gambar 6.

Berdasarkan Gambar 6 dan Gambar 7 hasil pengujian model PID terlihat adanya hubungan antara Set Point (SP), Process Variabel (PV), bukaan valve 
(OP). SP adalah nilai variabel proses yang diinginkan, PV adalah besaran yang menyatakan keadaan proses, dan OP adalah controller output yang sebelumnya diubah dulu oleh transducer menjadi sinyal pneumatik untuk mengatur bukaan control valve sehingga didapatkan temperature yang diinginkan. Terlihat grafik SP cenderung tetap. Grafik PV bergerak naik dan turun untuk menyamakan nilainya dengan SP. Perubahan naik turunnya PV berpengaruh terhadap persentase sinyal kontrol (OP). Terlihat pada tabel 4.1 respon waktu rata-ratanya 0,815 menit. Sehingga dari hasil diketahui bahwa dengan nilai $\mathrm{Kc}=8, \mathrm{Ti}=1$ dan $\mathrm{Td}=0$ sebuah sistem pengendalian suhu dapat diterapkan untuk mendapatkan waktu yang paling optimal. Waktu yang optimal dapat memperkecil kemungkinan kecelakaan kerja, kerusakan peralatan, dan memperkecil keragaman kualitas dan produktivitas. Sehingga nantinya akan diperoleh kuantitas dan kualitas produk utama (yield) yang maksimum dengan biaya produksi minumum. Pada tabel 4.2 respon waktu rata-ratanya 1,257 menit, sehingga dari hasil diketahui bahwa dengan nilai $\mathrm{Kc}=10, \mathrm{Ti}=4$ dan $\mathrm{Td}=0$ sebuah sistem pengendalian suhu yang memiliki waktu yang kurang optimal.

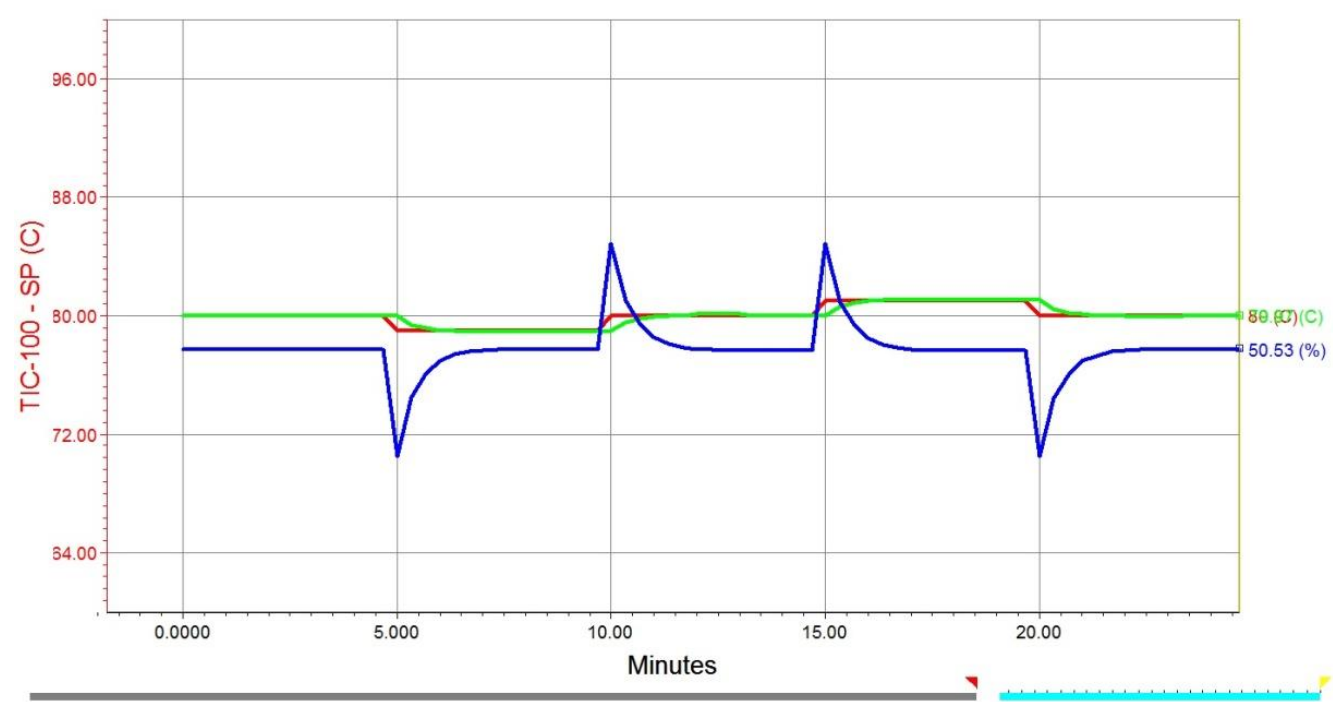

Gambar 6 Grafik hasil pengujian model PID dengan nilai $\mathrm{Kc}=10, \mathrm{Ti}=4$,

dan $\mathrm{Td}=0$
Keterangan Gambar:
Garis proses variabel $(\mathrm{P}, \mathrm{T}, \quad$ Garis setpoint (SP),

Garis bukaan valve (OP) 
Pengujian model PID membutuhkan penalaan (tuning) untuk mengatur agar control valve (final control element) merespon error. Masalah penyetelan kontroler proporsional $(\mathrm{Kc})$ adalah sifatnya yang selalu menghasilkan offset. Hal ini disebabkan oleh sifat dasar pengendali proportional yang membutuhkan error untuk menghasilkan output. Error adalah selisih antara setpoint atau nilai yang diinginkan dikurangi pressure value atau nilai yang didapat. Error terbagi menjadi error positif dan error negatif. Jika perubahan setpoint berupa suhu semakin tinggi akan menghasilkan nilai error yang positif sedangkan jika perubahan setpoint rendah akan menghasilkan error negative. Apabila ada perbedaan nilai setpoint dan nilai pressure value maka controller akan menghasilkan error yang mempengaruhi aksi kendali. Dengan demikian, sistem secara cepat mengubah keluaran sampai diperoleh nilai error sekecil mungkin.

Nilai Kc lebih besar daripada nilai lainnya dikarenakan untuk mengurangi offset. Akan tetapi nilai Kc yang terlalu besar akan menyebabkan sistem cenderung tidak stabil (terjadi osilasi) sedangkan apabila nilai Kc terlalu kecil akan menyebabkan penyimpangan variabel proses (PV) proses terlalu besar. Karena Kc menghasilkan offset maka perlu ditambahkan kendali integral yang berfungsi untuk menghilangkan offset. Sama halnya dengan Kc, nilai Ti yang terlalu besar akan menyebabkan sistem berosilasi dan apabila terlalu kecil akan mengakibatkan overshoot.

Konversi pada reaktor dipengaruhi oleh beberapa faktor yaitu pengaruh suhu, perbandingan mol, tipe, waktu tinggal, dan ukuran reaktor. Pada penelitian ini, konversi berubah-ubah karena suhu keluaran reactor yang diganggu dimana akan mempengaruhi nilai konversi itu sendiri. Persamaan Arrhenius menyatakan bahwa semakin tinggi suhu reaksi, maka nilai dari kecepatan reaksi juga akan semakin besar. Apabila kecepatan reaksi semakin besar maka hidrolisa akan berjalan lebih cepat sehingga menghasilkan nilai konversi yang lebih besar. Akan tetapi, kenaikan suhu akan menggeser kesetimbangan sehingga perlu dicari suhu optimum dalam operasi reaktor. Pada penelitian ini, kondisi operasi reaktor dengan suhu optimum $80{ }^{\circ} \mathrm{C}$ menghasilkan konversi yaitu sebesar 96,60\%. 


\section{Kesimpulan dan Saran}

\section{Kesimpulan}

Berdasarkan hasil yang telah diperoleh pada penelitian ini maka dapat disimpulkan nilai $\mathrm{Kc}=8, \mathrm{Ti}=1, \mathrm{Td}=0$ didapatkan respon waktu tercepat dengan respon waktu rata-rata 0,815 menit. Nilai $\mathrm{Kc}=10, \mathrm{Ti}=4, \mathrm{Td}=0$ didapatkan respon waktu terlama dengan respon waktu rata-ratanya 1,257 menit. Waktu yang optimal dapat memperkecil kemungkinan kecelakaan kerja, kerusakan peralatan, dan memperkecil keragaman kualitas dan produktivitas. Kondisi operasi reaktor dengan suhu optimum $80^{\circ} \mathrm{C}$ menghasilkan konversi tertinggi yaitu sebesar 96,64 $\%$.

\section{Saran}

Berdasarkan penelitian yang telah dilakukan maka disarankan untuk peneliti berikutnya dapat melanjutkan penelitian kontrol PID dengan menggunakan level, tekanan, dan laju alir sebagai set point untuk mengetahui lebih dalam tentang control PID.

\section{Daftar Pustaka}

Binus, L. (2011) 'Teori PID’, pp. 6-27.

Budiyanto, S. M. R. W. N. E. (2014) 'Simulasi Kontrol PID untuk Mengatur Putaran Motor AC', Prosiding SNST ke-5, pp. 23-28.

Dengan, K. and Logika, P. (2010) 'konvensional', 3(1).

Juanda, A. (2009) 'Perancangan Self-Tuning PID’, pp. 5-23.

Logic, F. (2013) 'Perbandingan Sistem Pengontrolan Pid Konvensional Dengan Pengontrolan Cmac, Fuzzy Logic Dan Ann Pada Water Level', 17(3), pp. 129-141.

'Module : 2 Lecture : 7 FORMIC ACID' (1855), pp. 1-5.

Mulya, A. (2004) 'Pengaturan Level Ketinggian Air Menggunakan Kontrol PID', Jurnal Teknik Elektro, 4(2), pp. 79-84. doi: 10.9744/jte.4.2. 
Mulyawan, H. (2009) ‘Bab II Tinjauan Pustaka’, pp. 1-17.

Pereira, C. J. and Leib, T. M. (2008) Section 19. Reactors, Perry's Chemical Engineers' Handbook. doi: 10.1036/0071511423.

Prasetyo, D. et al. (2016) Analisa Kinerja Sistem Pengendalian Pid Pada Three Phase Separator Analysis Of System Performance Pid Controller On Three Phase Separator.

'Procededing SNTEI 2015 By Kartika Dewi.pdf.

Proses, P. (2010) 'Pengendalian proses'.

Purwanti, A., Kimia, J. and Industri, F. T. (2009) 'Pemanfaatan metoda newtonraphson dalam perancangan reaktor alir tangki berpengaduk', 2, pp. 185193.

Reutemann, W. and Kieczka, H. (2000) 'Formic Acid', Ullmann's Encyclopedia of Industrial Chemistry. doi: 10.1002/14356007.a12_013.

Sensor, T. K., Hafid, M. and Agustinah, T. (2014) 'Perancangan Kontroler Fuzzy PD untuk Kontrol', 3(1), pp. 64-69.

Setiawan, B. I. (1997) 'Perancangan Robot Auto Line Follower yang Menerapkan Metode Osilasi Ziegler-Nichols Untuk Tuning Parameter PID pada Kontes Robot Indonesia', 1, pp. 1-6.

Utara, U. S. (2005) 'Bab II Tinjauan Pustaka 2.1 Produksi sinar-X', pp. 5-16.

W., R., Missen, C. A. and Saville, M. and B. A. (1999) Ronald W. Missen Charles A. Mims Bradley A. Saville, New York.

Wijaya, E. C. et al 'Auto Tuning', pp. 1-12. 